\title{
Survival of Patients with Small-Cell Lung Cancer Treated at Tertiary Hospitals in the East of Thailand, 2007-2016: A Retrospective Study
}

\author{
Sitthi Sukauichai ${ }^{*}$, Chokaew Tovanabutra ${ }^{2}$, Thapana Tangchewinsirikul2, \\ Sirentra Wanglikitkoon ${ }^{2}$, Kittisak Chomprasert ${ }^{2}$, Teerayuth Namkanitsorn ${ }^{3}$, \\ Passakorn Wanchaijiraboon ${ }^{3}$, Annop Kittiwarawut ${ }^{4}$
}

\author{
${ }^{1}$ Department of Chemotherapy, Chonburi Cancer Hospital, Chonburi, Thailand \\ ${ }^{2}$ Department of Radiation Oncology, Chonburi Cancer Hospital, Chonburi, Thailand \\ ${ }^{3}$ Department of Internal Medicine, Prapokklao Hospital, Chanthaburi, Thailand \\ ${ }^{4}$ Department of Internal Medicine, Chonburi Hospital, Chonburi, Thailand \\ Email: *maxstmdcu@yahoo.com
}

How to cite this paper: Sukauichai, S., Tovanabutra, C., Tangchewinsirikul, T., Wanglikitkoon, S., Chomprasert, K., Namkanitsorn, T., Wanchaijiraboon, P. and Kittiwarawut, A. (2019) Survival of Patients with Small-Cell Lung Cancer Treated at Tertiary Hospitals in the East of Thailand, 2007-2016: A Retrospective Study. Advances in Lung Cancer, 8, 1-14. https://doi.org/10.4236/alc.2019.81001

Received: January 31, 2019

Accepted: March 28, 2019

Published: March 31, 2019

Copyright ( 2019 by author(s) and Scientific Research Publishing Inc. This work is licensed under the Creative Commons Attribution International License (CC BY 4.0).

http://creativecommons.org/licenses/by/4.0/ (c) (i) Open Access

\begin{abstract}
Objective: The objective of the study was to determine the survival of patients with small-cell lung cancer treated at tertiary hospitals in the East of Thailand. Materials and methods: The researchers conducted this retrospective study by reviewing medical records of patients with small-cell lung cancer treated at Chonburi Cancer Hospital and Prapokklao Hospital from January 2007 to December 2016 and monitored via follow-up until December 2018. Results: This study enrolled 54 patients with a median follow-up time of 8.5 months. The median age of patients was 63 years old. Most patients were male (83.3\%) and had a history of smoking (90.7\%), and $31.4 \%$ had clinical superior vena cava obstruction at initial treatment. The Eastern Cooperative Oncology Group performance status $0-1$ was noted for $61.1 \%$ of the study population. Median survival time of patients with limited-stage and extensive-stage small cell lung cancer who received systemic chemotherapy and/or radiotherapy was 17.01 months (95\% CI, $12.01-22.01)$ and 8.14 months (95\% CI, 7.19 - 9.10), respectively, and that of patients receiving supportive care was 2.3 months (95\% CI, 0.75 - 4.03). However, the median survival time of patients with extensive-stage small-cell lung cancer receiving only palliative chemotherapy was 5.9 months (95\% CI, $0.32-17.51)$. Conclusions: The median survival time of patients with limited-stage small-cell lung cancer treated in the East of Thailand was comparable to those of landmark studies; however, the survival of patients with extensive-stage small-cell lung cancer was shorter than those of Phase III trials. A multidisciplinary team was necessary to improve the quality of patient care.
\end{abstract}




\section{Keywords}

Survival, Small Cell Lung Cancer, Tertiary Hospitals, Thailand

\section{Introduction}

Lung cancer is the leading cause of cancer-related deaths worldwide [1]. Small cell lung cancer (SCLC) accounts for 10\% - 13\% of lung cancers in Western countries [2] [3]. In Thailand, however, it represents approximately $6 \%-7 \%$ of lung cancer [4].

For more than a few decades, the standard of care in patients with limited-stage (LS) SCLC has remained concurrent chemoradiation, and for patients with extensive-stage (ES) SCLC has been chemotherapy [5]. Recently, immunotherapy has played a crucial role in improving the survival of ES-SCLC patients when combined with standard treatment [6].

Median survival time (MST) of SCLC patients in Phase III trials with LS and ES was 17 to 30 months and 7.1 to 12.8 months, respectively [6]-[14]. In the real world, previous reports revealed that the survival of SCLC patients with LS and ES was 10.3 to 18.2 months and 5.5 to 10.2 months, respectively [15] [16] [17].

The purpose of this study was to determine the survival of SCLC patients treated at tertiary hospitals in the East of Thailand. Also, this study assessed treatment patterns and prognostic factors for survival.

\section{Materials and Methods}

The researchers retrospectively reviewed medical records of patients diagnosed with SCLC or neuroendocrine carcinoma (NECA) of the lung at Chonburi Cancer Hospital $(\mathrm{CCH})$ in the Chonburi province and Prapokklao Hospital $(\mathrm{PKH})$ in the Chanthaburi province, from January 2007 to December 2016. Inclusion criteria included histologically or cytologically confirmed SCLC or NECA, age equal or more than 18-year-old, and patients receiving treatment at $\mathrm{CCH}$ or $\mathrm{PKH}$. Exclusion criteria included equivocal pathology, unknown stage, receiving chemotherapy from other hospitals, unknown last status, and concomitant malignancy. All patients were registered at the tumor registry at $\mathrm{CCH}$. The patients' medical files were reviewed and recorded for their characteristics, stage, treatment, and treatment outcomes.

The staging consisted of a CT scan of the chest, including the adrenal gland, while bone scan and brain imaging, including computed tomography (CT) or magnetic resonance imaging (MRI), was performed based on the discretion of the oncologists. Staging according to 7th TNM (tumor, node, metastasis) Classification of Malignant Tumors and Veterans Administration Lung Group (VALG) was used in this study. LS was defined as Stages I-III, with disease confined in one hemithorax, the mediastinum, or bilateral supraclavicular area, and could be safely treated with definitive radiation dose. ES was Stage IV (M1) in- 
cluding T3-4 due to having too many lung nodules or large tumor/nodal volume to be safely treated with definitive dose radiotherapy [5] [18].

Superior vena cava (SVC) obstruction was defined as having the medical record showing symptoms and signs of SVC obstruction such as superficial vein dilatation at chest wall or neck, facial or arm edema [19]. Hyponatremia was defined as initial serum sodium level $\leq 130 \mathrm{mMol} / \mathrm{L}$ [20].

Treatment modalities, including sequence, dosage, and regimen of radiation and chemotherapy, were based on the discretion of radiation and medical oncologists. Carboplatin dose (milligram) was calculated based on Calvert formula, and the glomerular filtration rate was estimated using the Cockcroft-Gault formula [21]. Patients who relapsed or progressed within three months after completion of first-line chemotherapy were considered chemotherapy-resistant (C-RT); in contrast, those who progressed after three months after completion of first-line chemotherapy were defined as chemotherapy-sensitive (C-ST) [5] [18].

Definitive thoracic radiotherapy (TRT) was defined as radiation to the thoracic tumor with a conventional daily dose of 1.8 to 2.0 Gy per fraction with a curative aim, while palliative TRT was to radiate to the thoracic tumor with a higher dose, 2.5 to 5.0 Gy per fraction with palliative intention.

Response Evaluation Criteria in Solid Tumors version 1.1 was used to assess treatment response [22]. The response was evaluated after concurrent chemoradiation, and after chemotherapy in patients treated with sequential chemoradiation or palliative chemotherapy. MST was calculated from pathologic report date to date of death in patients receiving best supportive care and from date of starting treatment to date of death in patients treated with chemotherapy and/or radiation. The date of data cut-off was December 31, 2018.

\section{Statistical Analysis}

MST was calculated using the Kaplan-Meier method. Sixteen variables were included in the analyses to identify prognostic factors for MST. Comparisons of cumulative survival were obtained by univariate analyses using the log-rank test, and multivariate analyses were performed using the Cox proportional hazard regression. A p $<0.05$ in univariate analysis and multivariate analysis was considered a statistically significant difference. SPSS for Windows, Version 16.0. (SPSS Inc., Chicago, IL) was used in this study.

\section{Results}

We reviewed 109 patient medical files. Of these, however, 55 were excluded, owing to the following reasons: 33 received chemotherapy from other hospitals, eight had uncertain pathology, six medical files were lost, four had inadequate staging workup, three had an unknown last status, and one had concomitant cancer. Therefore, 54 patients met the inclusion criteria.

\section{Patient Characteristics}

The baseline characteristics of patients are listed in Table 1. In their clinical courses, symptomatic SVC obstruction was found in 19 patients $(\mathrm{LS}=4$, ES = 
15), 17 of which (31.4\%) presented with SVC obstruction. The median level of serum sodium of patients having hyponatremia was $120 \mathrm{mMol} / \mathrm{L}$ (range, 116 126). Moreover, one patient had acromegaly as a paraneoplastic syndrome of SCLC, while Cushing's syndrome was not found in the study.

Table 1. Patient characteristics.

\begin{tabular}{|c|c|c|}
\hline \multicolumn{2}{|c|}{$\mathrm{N}=54$} & $\mathrm{~N}(\%)$ \\
\hline \multicolumn{2}{|c|}{ Age, year (range) } & $63(41-78)$ \\
\hline \multirow{2}{*}{ Sex } & Male & $45(83.3)$ \\
\hline & Female & $9(16.7)$ \\
\hline \multirow{2}{*}{ Age } & $<70$ & $34(63.0)$ \\
\hline & $\geq 70$ & $20(37.0)$ \\
\hline \multirow{2}{*}{ Health fund } & UCS/SSS & $41(87.0) / 1(1.9)$ \\
\hline & GSEO & $6(11.1)$ \\
\hline \multirow{2}{*}{ Smoking } & Yes & $49(90.7)$ \\
\hline & No/NA & $1(1.9) / 4(7.4)$ \\
\hline \multirow{2}{*}{ SVCO } & Yes & $19(35.2)$ \\
\hline & No & $35(64.8)$ \\
\hline \multirow{2}{*}{ Hyponatremia } & Yes & $9(16.7)$ \\
\hline & No/NA & $33(61.1) / 12(22.2)$ \\
\hline \multirow{3}{*}{ ECOG performance s } & $0-1$ & $33(61.1)$ \\
\hline & $2-4, \mathrm{NA}^{*}$ & $21(38.9)$ \\
\hline & Biopsy & $45(83.3)$ \\
\hline Pathology \# & Cytology & $9(16.7)$ \\
\hline \multirow{2}{*}{$\begin{array}{l}\text { VALG } \\
\text { staging }\end{array}$} & Limited & $15(27.8)$ \\
\hline & Extensive & $39(72.2)$ \\
\hline \multirow{3}{*}{ TNM staging } & III-A & $9(16.7)$ \\
\hline & III-B & $13(24.1)$ \\
\hline & IV & $32(59.3)$ \\
\hline \multirow{3}{*}{ Tumor } & $1 / 2$ & $3(5.6) / 9(16.7)$ \\
\hline & $3 / 4$ & $14(25.9) / 24(44.4)$ \\
\hline & $\mathrm{x}$ & $4(7.4)$ \\
\hline \multirow{3}{*}{ Node } & $0 / 1$ & $2(3.7) / 1(1.9)$ \\
\hline & $2 / 3$ & $22(40.7) / 21(38.9)$ \\
\hline & $\mathrm{x}$ & $8(14.8)$ \\
\hline Metastasis & $0 / 1$ & $22(40.7) / 32(59.3)$ \\
\hline
\end{tabular}

Abbreviations: ECOG, Eastern Cooperative Oncology Group; GSEO, government or state enterprise officer: $\mathrm{N}$, lymph node; NA, data not available; $\mathrm{M}$, metastasis; SSS, social security scheme; T, tumor; UCS, universal coverage scheme; VALG, Veterans Administration Lung Group. ${ }^{\star}$ ECOG performance status: $2(\mathrm{n}=11), 3$ $(\mathrm{n}=6), 4(\mathrm{n}=2)$, and NA $(\mathrm{n}=2)$. \# site of tissue diagnosis: bronchus $(28)$, supraclavicular or cervical lymph nodes (15), lung (7), others (4). 
In addition to $\mathrm{CT}$ chest and upper abdomen as a staging process, brain imaging was done in 13 patients (24.1\%; CT $\operatorname{scan}=11, \mathrm{MRI}=2$; LS $=4 / 15$ [26.7\%], $\mathrm{ES}=9 / 39$ [23.1\%]). Moreover, a bone scan was performed in 8/54 (14.8\%) patients; LS = 4/15 (26.7\%), ES = 4/39 (10.3\%).

In terms of the correlation between VALG staging and TNM classification, all the patients in Stage III-A and half of the patients in Stage III-B $(n=6)$ were classified as LS. On the other hand, the others in Stage III-B ( $n=7$; because of T4 tumor-a massive thoracic tumor or separate tumor in the same ipsilateral lobe different from the primary tumor) and all of Stage IV were classified as ES.

The subtype of the tumor was small cell $(n=50)$, large cell $(n=2)$, and mixed small and large cell carcinoma $(n=2)$. Additionally, immunohistochemistry (IHC) panel of neuroendocrine differentiation markers was stained in 31/45 (68.9\%) biopsy specimens, and the positivity percent of each marker was shown in Table 2.

Survival

At the time of analysis, December 31, 2018, with a median follow-up time of 8.5 months, 50 patients $(92.5 \%)$ had died. Four patients were alive. Of these, three patients were regularly monitored via follow-up and lived without the disease, whereas the other one received supportive care.

MST of the patients receiving chemotherapy and/or radiation with LS ( $\mathrm{n}=14$ ) and ES $(\mathrm{n}=32)$ was 17.01 months (95\% CI, $12.01-22.01)$ and 8.14 months (95\% CI, 7.19 - 9.10), respectively, and that of patients who received supportive care (n = 8) was 2.39 months (95\% CI, 0.75 - 4.03), as shown in Figure 1. Moreover, the MST of patients based on stages and various treatment modalities is shown in Table 3.

\section{Treatment and Efficacy}

Systemic intravenous chemotherapy was provided in 46 patients $(85.1 \%)$ and listed in Table 4. The two most common chemotherapies as the first-line regimen were cisplatin/etoposide $(\mathrm{n}=29)$ and carboplatin/etoposide $(\mathrm{n}=14)$; moreover, their dosage is shown in Table 5. Median interval of each cycle for cisplatin/etoposide was 28.0 days (range, 21.0 - 34.3) and for carboplatin/etoposide was 26.6 days (range, 21.0 - 41.0).

Table 2. Immunohistochemistry staining.

\begin{tabular}{cccc}
\hline IHC panel & Result & Number & Positivity (\%) \\
\hline Chromogranin $(\mathrm{n}=24)$ & Positive & 19 & 79.1 \\
Synaptophysin $(\mathrm{n}=22)$ & Negative & 5 & 90.9 \\
CD $56(\mathrm{n}=18)$ & Positive & 20 & 94.4 \\
NSE $(\mathrm{n}=2)$ & Pegative & 2 & \\
& Negative & 17 & 50.0 \\
\hline
\end{tabular}

Abbreviations: IHC, immunohistochemistry; n, number; NSE, neuron-specific enolase. 


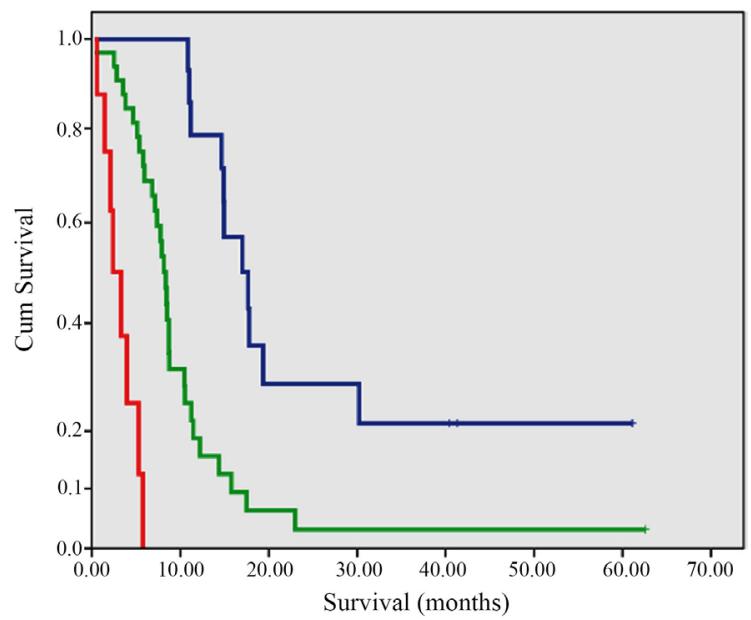

Figure 1. Survival based on stages and treatments. Graph depicts limited stage with treatment (blue), extensive stage with treatment (green), and best supportive care (red).

Table 3. Median survival based on stages and various treatment modalities.

\begin{tabular}{|c|c|c|c|c|c|c|}
\hline Stage & Treatment & $\begin{array}{c}\text { Concurrent } \\
\text { Chemotherapy } \\
\text { + Definitive } \\
\text { TRT }\end{array}$ & $\begin{array}{c}\text { Sequential } \\
\text { Chemotherapy } \\
\text { + Definitive } \\
\text { TRT }\end{array}$ & $\begin{array}{c}\text { Sequential } \\
\text { Chemotherapy } \\
+ \text { Palliative } \\
\text { TRT }\end{array}$ & $\begin{array}{c}\text { Palliative } \\
\text { Chemotherapy* }\end{array}$ & $\mathrm{BSC}^{*}$ \\
\hline \multirow{3}{*}{$\begin{array}{l}\text { Limited } \\
\mathrm{N}=15\end{array}$} & $\mathrm{~N}$ & 6 & 4 & 3 & 1 & 1 \\
\hline & MST & 29.09 & 15.98 & 14.91 & 11.00 & 3.94 \\
\hline & $95 \%$ CI & $10.84-61.10$ & $11.20-31.22$ & $14.65-19.38$ & - & - \\
\hline \multirow{3}{*}{$\begin{array}{c}\text { Extensive } \\
\mathrm{N}=39\end{array}$} & $\mathrm{~N}$ & 2 & 6 & 9 & 15 & 7 \\
\hline & MST & 7.77 & 8.64 & 12.22 & 5.94 & 2.39 \\
\hline & $95 \%$ CI & $7.39-8.14$ & $5.78-11.26$ & $2.49-62.55$ & $0.32-17.51$ & $0.59-5.74$ \\
\hline
\end{tabular}

Abbreviations: BSC, best supportive care; CI, confidence interval; MST, median survival time (months); N, number; TRT, thoracic radiotherapy. ${ }^{*}$ including palliative radiotherapy to thoracic tumor, bone, or brain.

Table 4. Chemotherapy regimen.

\begin{tabular}{ccc}
\hline Regimen & First-Line $(\mathrm{n}=46)$ & Second-Line $(\mathrm{n}=9)$ \\
\hline Cisplatin/etoposide & 29 & 0 \\
Carboplatin/etoposide & 14 & 3 \\
Carboplatin/paclitaxel & 2 & $5^{\star *}$ \\
Others & $1^{\star}$ & $4(1-6)$ \\
Median cycles (range) & $5(1-7)$ &
\end{tabular}

${ }^{*}$ Weekly carboplatin with radiotherapy, ${ }^{*}$ paclitaxel $(\mathrm{n}=3)$, paclitaxel/cisplatin $(\mathrm{n}=1)$, and cyclophosphamide/doxorubicin/vincristine $(\mathrm{n}=1)$.

Table 5. Dosage of platinum/etoposide as first-line regimen.

\begin{tabular}{cccc}
\hline Agent & Median Dose (Range) & Unit & Day \\
\hline Cisplatin, $\mathrm{n}=20$ & $71.6(50.0-90.3)$ & $\mathrm{mg} / \mathrm{m}^{2}$ & 1 \\
Carboplatin, $\mathrm{n}=11$ & $4.1(3.1-6.2)$ & AUC & 1 \\
Etoposide, $\mathrm{n}=31$ & $92.1(72.4-110.0)$ & $\mathrm{mg} / \mathrm{m}^{2}$ & $1-3$
\end{tabular}

Abbreviations: AUC, area under curve; $\mathrm{m}^{2}$, meter square of body surface area. 
Treatment response assessed in 46 patients receiving first-line therapy showed complete response in $13.0 \%(n=6)$, partial response $(P R)$ in $54.3 \%(n=25)$, stable disease $(S D)$ in $13.0 \%(n=6)$, progression of disease $(P D)$ in $2.2 \%(n=1)$, and $17.4 \%$ were not available $(\mathrm{NA} ; \mathrm{n}=8)$. Of the $15 \mathrm{ES}$ patients receiving palliative chemotherapy, 53.3\% $(n=8)$ were in $P R, 6.7(n=1)$ were in $\mathrm{SD}, 6.7 \%(\mathrm{n}=$ 1) were in $\mathrm{SD}$, and $33.3 \%(n=5)$ were NA.

TRT was administered with once-daily fractionation to all patients. Radiation was delivered with a two-dimensional (2-D) technique (via linear accelerator, $\mathrm{n}$ $=18$; Cobalt-60, $\mathrm{n}=14)$ and intensity-modulated radiotherapy $(\mathrm{n}=2)$. Median dose/median fraction for definitive TRT $(n=18)$ was 50.0 Gy $(95 \%$ CI, 7.2 $60.0) / 25$ fractions (95\% CI, 4 - 33), and for palliative TRT $(\mathrm{n}=16)$ was $28.0 \mathrm{~Gy}$ (95\% CI, 10.0 - 30.0)/10 fractions (95\% CI, 2 - 10). As for definitive TRT, 15 patients $(83.3 \%)$ completed the course of radiation, while three patients could not because of disease progression (one due to pleural effusion, one due to spinal cord compression, and one due to liver metastasis) during TRT.

Regarding the sequential chemoradiation group, for LS $(n=7)$, this study showed chemotherapy first in four cases (definitive TRT, $n=3$ and palliative TRT, $\mathrm{n}=1$ ) and radiation first in three (definitive TRT, $\mathrm{n}=1$ and palliative TRT, $n=2)$. For ES $(n=15)$, it showed chemotherapy first in nine patients (definitive TRT, $\mathrm{n}=5$ and palliative TRT, $\mathrm{n}=4$ ) and radiation first in six patients (definitive TRT, $\mathrm{n}=1$; palliative TRT, $\mathrm{n}=5$ ).

Regarding SVC obstruction management, this study represented clinical or symptomatic SVC obstruction in 19 patients. Treatment modalities in these patients with LS were concurrent chemoradiation $(n=1)$ and sequential chemotherapy and palliative TRT $(n=3)$. One patient with ES received concurrent chemoradiation, two received sequential chemotherapy and definitive TRT, three received chemotherapy alone, three received palliative TRT alone, and six received sequential chemotherapy and palliative TRT.

Prophylaxis cranial irradiation (PCI) was administered in three patients $(5.5 \%$; LS $=2$, ES $=1)$. Reasons for not performing PCI included best supportive care $(n=8)$, poor Eastern Cooperative Oncology Group (ECOG) performance status $(n=7)$, brain metastasis before PCI was offered $(n=6)$, patients lost to follow-up $(n=5)$, no response to prior treatment $(n=4)$, patient refusal $(n=3)$, and no record $(n=18)$.

Regarding second-line therapy, C-RT and C-ST were found in four patients in each group. The median time to tumor progression after completion of first-line treatment for C-RT and C-ST groups was 5.5 months (95\% CI, 4.0 - 11.1) and 2.3 months ( $95 \%$ CI, 1.0 - 3.0) months, respectively. Several second-line chemotherapy regimens (including their efficacy) were paclitaxel $(\mathrm{SD}=1, \mathrm{NA}=1$ ), paclitaxel/carboplatin $(\mathrm{PR}=1)$, and cyclophosphamide/doxorubicin/vincristine $(\mathrm{NA}=1)$ for $\mathrm{C}-\mathrm{RT}$, and paclitaxel $(\mathrm{PD}=1)$, etoposide/carboplatin $(\mathrm{SD}=1)$, paclitaxel/cisplatin $(\mathrm{PR}=1)$, and paclitaxel/carboplatin $(\mathrm{PR}=1)$ for C-ST.

The median line of chemotherapy was one. Only two patients received chemotherapy as third- and fourth-line regimens. 


\section{Univariate and Multivariate Analysis for Survival}

Sixteen variables including sex (male/female), age group $(<70 / \geq 70$ years), health fund (universal coverage and social security schemes/ government or state enterprise officer, ECOG performance status (0-1/2-4 and NA), VALG staging (LS/ES), TNM staging (III/IV and III-A/III-B/IV), the presence or not of these factors including SVC obstruction, spinal cord compression, hyponatremia, liver, pleural, distance lymph node, brain, bone, and adrenal gland metastases were analyzed by the Kaplan-Meier method. Univariate analysis outcomes indicated that ECOG performance status 2 to 4 and NA, ES, Stage IV, lung metastasis, and liver metastasis were unfavorable prognostic factors for survival (Table 6).

The significant prognostic factors $(\mathrm{p}<0.05)$ in the univariate analysis, including ECOG performance status, VALG staging, and TNM staging, were further analyzed in the Cox-regression model, except for lung and liver metastasis because of these factors resulting in changing staging. Multivariate analysis indicated that ECOG performance status 2 to 4 and NA, ES, Stage IV compared to Stage III and Stage IV compared to Stage III-A were unfavorable prognostic factors (Table 6). This did not show the difference for MST between Stage III-B and Stage III-A; however, if we compared MST of the patients in Stage IV to those in Stage III-B, it showed a statistically significant difference $(p=0.012)$.

Table 6. Significant prognostic factors for survival in univariate and multivariate analyses.

\begin{tabular}{|c|c|c|c|c|c|c|c|}
\hline \multirow{2}{*}{\multicolumn{2}{|c|}{ Factor }} & \multicolumn{3}{|c|}{ Univariate Analysis } & \multicolumn{3}{|c|}{ Multivariate Analysis } \\
\hline & & \multirow{2}{*}{$\begin{array}{l}\text { MST } \\
11.26\end{array}$} & \multirow{2}{*}{$\begin{array}{c}95 \% \text { CI } \\
9.71\end{array}$} & \multirow{2}{*}{$\begin{array}{c}\mathrm{p} \text {-value } \\
<0.001\end{array}$} & \multirow{2}{*}{$\begin{array}{l}\mathrm{HR} \\
1.00\end{array}$} & \multirow{2}{*}{$95 \%$ CI } & \multirow{2}{*}{ p-value } \\
\hline ECOG & $0-1$ & & & & & & \\
\hline $\begin{array}{l}\text { performance } \\
\text { status }\end{array}$ & $2-4, \mathrm{NA}$ & 5.38 & 2.68 & & 2.61 & $1.31-5.17$ & 0.006 \\
\hline Lung & No & 8.73 & $6.22-11.25$ & $<0.001$ & & & \\
\hline metastasis & Yes & 0.32 & -- & & & & \\
\hline Liver & No & 10.84 & $7.37-14.30$ & 0.001 & & & \\
\hline metastasis & Yes & 5.94 & $1.12-10.78$ & & & & \\
\hline VALG & Limited & 17.01 & 13.53 & $<0.001$ & 1.00 & & \\
\hline staging & Extensive & 7.39 & 4.98 & & 2.59 & $1.23-5.47$ & 0.012 \\
\hline TNM & III & 14.65 & 10.12 & $<0.001$ & 1.00 & & \\
\hline staging & IV & 5.94 & 3.67 & & 2.19 & $1.09-4.38$ & 0.026 \\
\hline & III-A & 17.01 & 10.97 & 0.001 & 1.00 & & \\
\hline $\begin{array}{l}\text { TNM } \\
\text { staging }\end{array}$ & III-B & 11.00 & 3.59 & & 1.44 & 0.55 & 0.453 \\
\hline & IV & 5.98 & 3.67 & & 2.74 & 1.08 & 0.033 \\
\hline
\end{tabular}

Abbreviations: CI, confidence interval; ECOG, Eastern Cooperative Oncology Group; HR, hazard ratio; MST, median survival time (months); NA, data not available; TNM, tumor/node/metastasis; VALG, Veterans Administration Lung Group. 


\section{Discussion}

In this retrospective study, the median patient age (61 years) was similar to that of other studies (61 to 63 years) [11] [12] [13]. Another similarity between this and other SCLC studies was that almost all patients in this study had a history of smoking. Interestingly, nearly one-third of patients in this study had SVC obstruction at the initial diagnosis, which was higher than the incidence reported by a previous study [23]. This might be explained by a referral bias; at that time, $\mathrm{CCH}$ was the only cancer center in the East of Thailand that had a radiation machine in the region.

Thanks to the unique morphology of SCLC, IHC was not required in all cases. Nonetheless, it was helpful in certain circumstances, including extensive crust artifact, equivocal pathologic feature, and making the diagnosis more confident [24] [25]. In this study, chromogranin-A and synaptophysin were the two most used markers to support the diagnosis.

Although standard treatment guidelines recommended using brain imaging and bone scan as part of staging workup [5] [18], this study revealed that less than a quarter of patients received such procedures. Brain imaging was performed in the same proportion of LS and ES patients, while a bone scan was done more often in patients with LS than in patients with ES.

The International Association for the Study of Lung Cancer (IASLC) recommended the use of TNM classification due to having a good correlation with survival outcomes, assisting in the selection of surgical candidates, benefitting the tumor registry, and receiving more details in the subset of LS or ES by VALG staging [5] [26]. In clinical practice in Thailand at that time, or even in recent Phase III studies [7], they still used VALG staging. This study found that all patients with Stage III-A and all patients with Stage IV could be classified into LS and ES, respectively. Interestingly, the median survival of patients with Stage III-B and IV in this study was precisely equal to those in the Surveillance, Epidemiology, and End Results database: 11.0 versus 11.0 months and 5.9 versus 6.0 months, respectively [26].

The survival of patients with LS receiving treatment was comparable to survival in some landmark studies (17.0 versus 17.0 to 23.0 months) [7] [10], but less than those of other studies (25.0 to 30.0 months) [8] [9]. However, if we explored a subgroup of LS patients receiving concurrent chemoradiation, the survival (29.0 months) was similar to those of such studies (Table 7) [7] [8] [9] [10]. Moreover, this study showed that the survival of patients with LS who received concurrent chemoradiation was higher than those of patients who received sequential treatment. As clearly proven by a Phase III trial, concurrent treatment could significantly prolong survival more than the sequential arm [8]. Unsurprisingly, not all patients with LS-SCLC received combined-modality treatment. In the real world, the treatment plan depended on several factors, such as patients' and physicians' discretions, patients' ECOG performance status, and waiting time to receive each treatment. For instance, in the United States, only $55 \%$ of patients with LS received combined-modality therapy, which 
was limited by the health insurance system, resulting in poorer survival [16].

As for ES, the survival of patients who received treatment was comparable to pivotal studies [11] [12] [13] [14]. Nonetheless, the survival of ES-SCLC patients receiving palliative chemotherapy in this study was shorter than those of such studies: 5.9 months versus 7.1 to 12.8 months (Table 8) [6] [11] [12] [13] [14]. This might be partly explained because nearly half of the ES patients (7/15) receiving chemotherapy had poor ECOG performance status (2 to 4 or NA; data not shown). Also, this study indicated ES patients who received either palliative or definitive TRT as part of their treatments could live longer. As clearly proven by two extensive, Phase III studies, TRT in ES-SCLC patients who responded to chemotherapy contributed to prolonged survival in these patients [27] [28].

Table 7. Selected phase III trials of limited-stage small-cell lung cancer.

\begin{tabular}{|c|c|c|c|c|c|c|c|c|}
\hline \multirow[b]{2}{*}{ Study } & \multirow[b]{2}{*}{$\mathrm{N}$} & \multirow{2}{*}{$\begin{array}{c}\text { Chemo } \times \\
\text { Cycles }\end{array}$} & \multicolumn{3}{|c|}{ Thoracic Radiotherapy } & \multirow[b]{2}{*}{ PCI } & \multirow{2}{*}{$\begin{array}{c}\text { MST } \\
\text { (Months) }\end{array}$} & \multirow[b]{2}{*}{$\mathrm{p}$-value } \\
\hline & & & $\begin{array}{l}\text { Concurrent } \\
\text { or Sequential }\end{array}$ & $\begin{array}{c}\text { Total Dose } \\
\text { (Gy) }\end{array}$ & $\begin{array}{c}\text { Once or } \\
\text { Twice Daily }\end{array}$ & & & \\
\hline $\begin{array}{c}\text { Turrisi AT } \\
\text { III, et al., } \\
1999 \text { [7] }\end{array}$ & $\begin{array}{l}206 \\
211\end{array}$ & $\mathrm{PE} \times 4$ & early C & 45 & $\begin{array}{l}\mathrm{O} ; 25 \times 1.8 \\
\mathrm{~T} ; 30 \times 1.5\end{array}$ & Yes & $\begin{array}{l}19.0 \\
23.0\end{array}$ & 0.04 \\
\hline $\begin{array}{c}\text { Takada M, } \\
\text { et al., } 2002 \\
{[8]}\end{array}$ & $\begin{array}{l}114 \\
114\end{array}$ & $\mathrm{PE} \times 4$ & $\begin{array}{l}\text { Sequential } \\
\text { early C }\end{array}$ & 45 & $\mathrm{~T} ; 30 \times 1.5$ & Yes & $\begin{array}{l}19.7 \\
27.2\end{array}$ & 0.02 \\
\hline $\begin{array}{c}\text { Faivre-Finn } \\
\text { C, et al., } \\
2017 \text { [9] }\end{array}$ & $\begin{array}{l}273 \\
274\end{array}$ & $\mathrm{PE} \times 4-6$ & early C & $\begin{array}{l}66 \\
45\end{array}$ & $\begin{array}{l}\mathrm{O} ; 33 \times 2.0 \\
\mathrm{~T} ; 30 \times 1.5\end{array}$ & Yes & $\begin{array}{l}25.0 \\
30.0\end{array}$ & 0.14 \\
\hline $\begin{array}{c}\text { Skarlos DV, } \\
\text { et al., } \\
2001 \text { [10] }\end{array}$ & $\begin{array}{l}42 \\
39\end{array}$ & $\mathrm{CE} \times 6$ & $\begin{array}{l}\text { early C } \\
\text { late } C\end{array}$ & 45 & $\mathrm{~T} ; 30 \times 1.5$ & Yes & $\begin{array}{l}17.5 \\
17.0\end{array}$ & NS \\
\hline
\end{tabular}

Abbreviations: C, concurrent; CE, carboplatin/etoposide; chemo, chemotherapy; MST, median survival time; N, number; NS, non-significant; O, once-daily dose; PE, cisplatin/etoposide; PCI, prophylactic cranial irradiation; $\mathrm{T}$, twice-daily dose.

Table 8. Selected phase III trials of extensive-stage small-cell lung cancer.

\begin{tabular}{|c|c|c|c|c|c|c|c|}
\hline Study & $\mathrm{N}$ & $\begin{array}{c}\text { Chemotherapy } \\
\text { Regimen }\end{array}$ & Cycles & TRT & PCI & $\begin{array}{c}\text { MST } \\
\text { (Months) }\end{array}$ & $\mathrm{p}$-value \\
\hline $\begin{array}{c}\text { Noda K, } \\
\text { et al., } 2002[11]\end{array}$ & $\begin{array}{l}77 \\
77\end{array}$ & $\begin{array}{l}\mathrm{PE} \\
\mathrm{PI}\end{array}$ & 4 & No & No & $\begin{array}{c}9.4 \\
12.8\end{array}$ & 0.002 \\
\hline $\begin{array}{c}\text { Neill HB, } \\
\text { et al., } 2005 \text { [12] }\end{array}$ & $\begin{array}{l}282 \\
283\end{array}$ & $\begin{array}{l}\text { PE } \\
\text { PET }\end{array}$ & 6 & No & Optional & $\begin{array}{c}9.9 \\
10.6\end{array}$ & 0.169 \\
\hline $\begin{array}{c}\text { Lara PN Jr, } \\
\text { et al., } 2009 \text { [13] }\end{array}$ & $\begin{array}{l}327 \\
324\end{array}$ & $\begin{array}{l}\text { PE } \\
\text { PI }\end{array}$ & 4 & No & No & $\begin{array}{l}9.1 \\
9.9\end{array}$ & 0.71 \\
\hline $\begin{array}{c}\text { Hermes A, } \\
\text { et al., } 2008 \text { [14] }\end{array}$ & $\begin{array}{l}104 \\
105\end{array}$ & $\begin{array}{l}\mathrm{CE} \\
\mathrm{CI}\end{array}$ & 4 & No & Optional & $\begin{array}{l}7.1 \\
8.5\end{array}$ & 0.02 \\
\hline $\begin{array}{c}\text { Horn L, } \\
\text { et al., } 2018 \text { [6] }\end{array}$ & $\begin{array}{l}201 \\
202\end{array}$ & $\begin{array}{c}\mathrm{CE}+\mathrm{A} \text { then } \mathrm{A} \\
\mathrm{CE}\end{array}$ & $\begin{array}{c}4 \text { then } \\
\text { MN (A) } \\
4\end{array}$ & No & Optional & $\begin{array}{l}12.3 \\
10.2\end{array}$ & 0.007 \\
\hline
\end{tabular}

Abbreviations: A, atezolizumab; CE, carboplatin/etoposide; CI, carboplatin/irinotecan; PE, cisplatin/etoposide; PI, cisplatin/irinotecan; MN, maintenance; N, number; MST, median survival time; PCI, prophylactic cranial irradiation; TRT, thoracic radiotherapy. 
PCI helped improve survival in LS-SCLC patients who responded to prior treatment and helped reduce symptomatic brain metastasis both in LS-SCLC and ES-SCLC and was recommended by treatment guidelines [5] [18]. However, PCI was rarely performed in this study due to the reasons mentioned previously.

Regarding first-line chemotherapy regimens, the most used chemotherapy was platinum/etoposide. Replacing etoposide as a first-line regimen [11] [13], irinotecan was not approved in the national list of essential medicines in Thailand, and no patients in this study received irinotecan. Therefore, platinum/etoposide remained a standard of care as a first-line chemotherapy regimen in SCLC.

This study reflected the situation of SCLC treatment in the East of Thailand, which was mostly based on individual physician's discretion and limited by the number of radiation machines in the region, resulting in an 11.4-week waiting period. Moreover, $\mathrm{CCH}$, with three radiation machines and four radiation oncologists, had to service 1900 new cases in 2018. Therefore, to ensure patient care quality and outcomes in the East of Thailand, we need more radiation oncologists, radiation machines, multidisciplinary care teams and meetings, leading to better outcomes in lung cancer patients, in terms of adequate and accurate staging and appropriate treatment modalities [29].

In a multivariate analysis, this study indicated that poor ECOG performance status (ECOG 2 to 4 or NA) was a poor prognostic factor for survival, which was similar to a report from Japan [30]. Furthermore, ES and Stage IV were also unfavorable prognostic factors for survival. Besides, when analyzing among Stage III-A, III-B, and IV, it indicated that Stage IV compared to Stage III-A and III-B had significantly shorter survival. However, this study could not show the survival difference between Stage III-B and III-A, limited by a minimal number of patients. Nevertheless, IASLC proposals clearly showed that TNM staging could show the difference for the survival of Stage IV versus III-B and of Stage III-B versus Stage III-A [26].

\section{Conclusion}

The MST of LS-SCLC patients in this real-world study was comparable to those of Phase III trials. However, the survival of ES-SCLC patients was shorter than those reported in pivotal studies. To ensure the quality of patient care and better outcomes, a multidisciplinary team and more medical resources, including radiation machines, were needed in the region. Poor ECOG performance status and advanced stages, including ES and Stage IV, resulted in adverse outcomes for survival.

\section{Acknowledgements}

The author sincerely thanks Dusit Sujirarat, who kindly provided suggestions on statistical analysis, the Cancer Registry Department of Chonburi Cancer Hospital, the Medical Records Department of Prapokklao Hospital, and other staff and physicians who cared for their patients in this study. 


\section{Conflicts of Interest}

The authors declare no conflicts of interest regarding the publication of this paper.

\section{References}

[1] International Agency Research on Cancer (2018) World Health Organization. Globocan 2018. https://gco.iarc.fr/today/data/factsheets/populations/900-world-fact-sheets.pdf

[2] Govindan, R., Page, N., Morgensztern, D., et al. (2006) Changing Epidemiology of Small-Cell Lung Cancer in the United States over the Last 30 Years: Analysis of the Surveillance, Epidemiologic, and End Results Database. Journal of Clinical Oncolo$g y, 24,4539-4544$. https://doi.org/10.1200/JCO.2005.04.4859

[3] Khakwani, A., Rich, A.L., Tata, L.J., et al. (2014) Small-Cell Lung Cancer in England: Trends in Survival and Chemotherapy Using the National Lung Cancer Audit. PLoS ONE, 9, e89426. https://doi.org/10.1371/journal.pone.0089426

[4] Chang, J.T., Jeon, J., Sriplung, H., et al. (2018) Temporal Trends and Geographic Patterns of Lung Cancer Incidence by Histology in Thailand, 1990 to 2014. Journal of Global Oncology, 4, 1-29. https://doi.org/10.1200/JGO.18.00013

[5] Jett, J.R., Schild, S.E., Kesler, K.A. and Kalemkerian, G.P. (2013) Treatment of Small Cell Lung Cancer. Diagnosis and Management of Lung Cancer, 3rd Ed: American College of Chest Physicians Evidence-Based Clinical Practice Guidelines. Chest, 143, e400S-e419S. https://doi.org/10.1378/chest.12-2363

[6] Horn, L., Mansfield, A.S., Szczęsna, A., et al. (2018) First-Line Atezolizumab plus Chemotherapy in Extensive-Stage Small-Cell Lung Cancer. The New England Journal of Medicine, 379, 2220-2229. https://doi.org/10.1056/NEJMoa1809064

[7] Turrisi, A.T., Kim, K., Blum, R., et al. (1999) Twice-Daily Compared with Once-Daily Thoracic Radiotherapy in Limited Small-Cell Lung Cancer Treated Concurrently with Cisplatin and Etoposide. The New England Journal of Medicine, 340, 265-271. https://doi.org/10.1056/NEJM199901283400403

[8] Takada, M., Fukuoka, M., Kawahara, M., et al. (2002) Phase III Study of Concurrent versus Sequential Thoracic Radiotherapy in Combination with Cisplatin and Etoposide for Limited-Stage Small-Cell Lung Cancer: Results of the Japan Clinical Oncology Group Study 9104. Journal of Clinical Oncology, 20, 3054-3060. https://doi.org/10.1200/JCO.2002.12.071

[9] Faivre-Finn, C., Snee, M., Ashcroft, L., et al. (2017) Concurrent Once-Daily versus Twice-Daily Chemoradiotherapy in Patients with Limited-Stage Small-Cell Lung Cancer (CONVERT): An Open-Label, Phase 3, Randomised, Superiority Trial. The Lancet Oncology, 18, 1116-1125. https://doi.org/10.1016/S1470-2045(17)30318-2

[10] Skarlos, D.V., Samantas, E., Briassoulis, E., et al. (2001) Randomized Comparison of Early versus Late Hyperfractionated Thoracic Irradiation Concurrently with Chemotherapy in Limited Disease Small-Cell Lung Cancer: A Randomized Phase II Study of the Hellenic Cooperative Oncology Group (HeCOG). Annals of Oncology, 12, 1231-1238. https://doi.org/10.1023/A:1012295131640

[11] Noda, K., Nishiwaki, Y., Kawahara, M., et al. (2002) Irinotecan plus Cisplatin Compared with Etoposide plus Cisplatin for Extensive Small-Cell Lung Cancer. The New England Journal of Medicine, 346, 85-91. https://doi.org/10.1056/NEJMoa003034

[12] Niell, H.B., Herndon, J.E., Miller, A.A., et al. (2005) Randomized Phase III Inter- 
group Trial of Etoposide and Cisplatin with or without Paclitaxel and Granulocyte Colony-Stimulating Factor in Patients with Extensive-Stage Small-Cell Lung Cancer: Cancer and Leukemia Group B Trial 9732. Journal of Clinical Oncology, 23, 3752-3759. https://doi.org/10.1200/JCO.2005.09.071

[13] Lara Jr., P.N., Natale, R., Crowley, J., et al. (2009) Phase III Trial of Irinotecan/Cisplatin Compared with Etoposide/Cisplatin in Extensive-Stage Small-Cell Lung Cancer: Clinical and Pharmacogenomic Results from SWOG S0124. Journal of Clinical Oncology, 27, 2530-2535. https://doi.org/10.1200/JCO.2008.20.1061

[14] Hermes, A., Bergman, B., Bremnes, R., et al. (2008) Irinotecan plus Carboplatin versus Oral Etoposide plus Carboplatin in Extensive Small-Cell Lung Cancer: A Randomized Phase III Trial. Journal of Clinical Oncology, 26, 4261-4267. https://doi.org/10.1200/JCO.2007.15.7545

[15] Kuo, Y.H., Lin, Z.Z., Yang, Y.Y., et al. (2012) Survival of Patients with Small Cell Lung Carcinoma in Taiwan. Oncology, 82, 19-24. https://doi.org/10.1159/000335084

[16] Pezzi, T.A., Schwartz, D.L., Mohamed, A.S.R., et al. (2017) Barriers to Combined-Modality Therapy for Limited-Stage Small Cell Lung Cancer. JAMA Oncology, 4, e174504. https://doi.org/10.1001/jamaoncol.2017.4504

[17] Steffens, C.C., Elender, C., Hutzschenreuter, U., et al. (2019) Treatment and Outcome of 432 Patients with Extensive-Stage Small Cell Lung Cancer in First, Second and Third Line-Results from the Prospective German TLK Cohort Study. Lung Cancer, 130, 216-225. https://doi.org/10.1016/j.lungcan.2019.02.026

[18] National Comprehensive Cancer Network (2019) Small Cell Lung Cancer, Version 1. https://www.nccn.org/professionals/physician_gls/pdf/sclc.pdf

[19] Wilson, L.D., Detterbeck, F.C. and Yahalom, J. (2007) Clinical Practice. Superior Vena Cava Syndrome with Malignant Causes. The New England Journal of Medicine, 356, 1862-1869. https://doi.org/10.1056/NEJMcp067190

[20] Johnson, B.E., Chute, J.P., Rushin, J., et al. (1997) A Prospective Study of Patients with Lung Cancer and Hyponatremia of Malignancy. American Journal of Respiratory and Critical Care Medicine, 156, 1669-1678. https://doi.org/10.1164/ajrccm.156.5.96-10075

[21] National Comprehensive Cancer Network (2019) NCCN Chemotherapy Order Templates (NCCN Templates ${ }^{\circledast}$ ). Appendix B: Carboplatin Dosing. https://www.nccn.org/professionals/OrderTemplates/PDF/appendix B.pdf

[22] Eisenhauer, E.A., Therasse, P., Bogaerts, J., et al. (2009) New Response Evaluation Criteria in Solid Tumours: Revised RECIST Guideline (Version 1.1). European Journal of Cancer, 45, 228-247. https://doi.org/10.1016/j.ejca.2008.10.026

[23] Sculier, J.P., Evans, W.K., Feld, R., et al. (1986) Superior Vena Caval Obstruction Syndrome in Small Cell Lung Cancer. Cancer, 57, 847-851.

https://doi.org/10.1002/1097-0142(19860215)57:4<847::AID-CNCR2820570427>3.0 .CO;2-H

[24] Thunnissen, E., Borczuk, A.C., Flieder, D.B., et al. (2017) The Use of Immunohistochemistry Improves the Diagnosis of Small Cell Lung Cancer and Its Differential Diagnosis. An International Reproducibility Study in a Demanding Set of Cases. Journal of Thoracic Oncology, 12, 334-346. https://doi.org/10.1016/j.jtho.2016.12.004

[25] Travis, W.D. (2010) Advances in Neuroendocrine Lung Tumors. Annals of Oncology, 21, vii65-vii71. https://doi.org/10.1093/annonc/mdq380

[26] Shepherd, F.A., Crowley, J., Houtte, P., et al. (2007) The International Association 
for the Study of Lung Cancer Lung Cancer Staging Project: Proposals Regarding the Clinical Staging of Small Cell Lung Cancer in the Forthcoming (Seventh) Edition of the Tumor, Node, Metastasis Classification for Lung Cancer. Journal of Thoracic Oncology, 2, 1067-1077. https://doi.org/10.1097/JTO.0b013e31815bdc0d

[27] Jeremic, B., Shibamoto, Y., Nikolic, N., et al. (1999) Role of Radiation Therapy in the Combined-Modality Treatment of Patients with Extensive Disease Small-Cell Lung Cancer: A Randomized Study. Journal of Clinical Oncology, 17, 2092-2099. https://doi.org/10.1200/JCO.1999.17.7.2092

[28] Slotman, B.J., van Tinteren, H., Praag, J.O., et al. (2015) Use of Thoracic Radiotherapy for Extensive Stage Small-Cell Lung Cancer: A Phase 3 Randomised Controlled Trial. The Lancet, 385, 36-42. https://doi.org/10.1016/S0140-6736(14)61085-0

[29] Denton, E. and Conron, M. (2016) Improving Outcomes in Lung Cancer: The Value of the Multidisciplinary Health Care Team. Journal of Multidisciplinary Healthcare, 9, 137-144. https://doi.org/10.2147/JMDH.S76762

[30] Minami, S., Ogata, Y., Ihara, S., Yamamoto, S. and Komuta, K. (2016) Retrospective Analysis of Outcomes and Prognostic Factors of Chemotherapy for Small-Cell Lung Cancer. Lung Cancer. Targets and Therapy, 7, 35-44.

https://doi.org/10.2147/LCTT.S100184 